\title{
Productivity of Smallholder Sugarcane Farmers in Swaziland: The Case of Komati Downstream Development Programme (KDDP) Farmers' Associations, 2005-2011
}

\author{
Mandla B. Dlamini ${ }^{1} \&$ Micah B. Masuku ${ }^{2}$ \\ ${ }^{1}$ P. O. Box C1037, Manzini Hub, Swaziland \\ ${ }^{2}$ Department of Agricultural Economics and Management, University of Swaziland, Swaziland \\ Correspondence: Micah B. Masuku, Department of Agricultural Economics and Management, University of \\ Swaziland, Swaziland. Tel: 268-7602-6557. E-mail: mbmasuku@uniswa.sz
}

Received: July 17, 2012 Accepted: August 15, 2012 Online Published: August 20, 2012

doi:10.5539/enrr.v2n4p1

URL: http://dx.doi.org/10.5539/enrr.v2n4p1

\begin{abstract}
Smallholder sugarcane growing is central to rural development and poverty alleviation in Swaziland. The main objective of smallholder sugarcane growing is to reduce poverty through increased household income as a result of sugarcane production. This study investigated the productivity of smallholder sugarcane farmers' associations under KDDP and the factors affecting sugarcane productivity. The study used data from 2004/05 to 2010/2011 production seasons for 15 smallholder sugarcane farmers' associations under KDDP. Production records for the farmers' associations were obtained from the Swaziland Water and Enterprise Development. The associations were purposively selected because of their experience in sugarcane production. Currently the productivity of the farmers' associations is 100.8 tonnes per ha. The Cobb-Douglas production function was used to identify the factors affecting sugarcane productivity. The results indicated that farm size, labour, basal fertilizer and topdressing fertilizer were statistically significant $(\mathrm{p}<0.05)$ in influencing sugarcane productivity. The adjusted R2 was 0.68 suggesting that $68 \%$ of the variation in sugarcane yield per hectare is explained by the explanatory variables. Farmers should take note to use labour according to the industry standards in order to get good yields. Basal fertilizer and top dressing fertilizer need to be applied in the recommended amounts. Good crop husbandry practices like timely weeding, fertilization, irrigation should be adopted to produce a good crop which will enhance productivity. Government and the private sector need to intensify the out grower technical services rendered to sugarcane farmers, so that they can improve the productivity of sugarcane farming.
\end{abstract}

Keywords: productivity, smallholder sugarcane farmers, Komati downstream development programme, Cobb-Douglas production function

\section{Introduction}

Agriculture plays a crucial role in the development of the economy of Swaziland and it provides inputs for agro-processing industries that form the backbone of the manufacturing sector. In 2008 it contributed 11.9 percent to the gross domestic product, while the agricultural activities conducted on the Swazi Nation Land contributed about 5 percent of the gross domestic product of the country (Thompson, 2010). Its contribution also includes its role as a supplier of raw materials to the agriculture industry, income support and food security to a large proportion of the rural households, a market for industrial products and an earner of foreign exchange. The agriculture sector supports the livelihood of 75 percent of the population, for whom 60 percent of the household income is derived from crops and livestock, while the remaining 15 percent is derived from wages and remittances, and informal sector activities. The diverse agricultural activities that occur in the country include sugarcane production, citrus fruit, vegetable crops, maize and other cereal crops, cotton, forestry and livestock production (Thompson, 2007).

According to the Swaziland Sugar Association (2011), the sugar industry in Swaziland dates back when irrigation projects were established at Bigbend in the Lowveld. This was y followed by the establishment of another mill at Mhlume, in the northern part of Swaziland and later a third mill at Simunye. Historically sugarcane production in Swaziland has been based on estates owned by the millers (UNCTAD, 2000), until 1962 when smallholder farmers under the Vuvulane irrigation scheme were brought on board through the assistance of 
Commonwealth Development Corporation. Since 1990, other smallholder sugarcane schemes have been introduced. This has been a result the industry setting aside special sucrose quotas and provision of technical assistance by the Swaziland Sugar Association and the Swaziland Government (UNCTAD, 2000; Westlake, 1995)

The sugar industry consists of the miller-cum planters, large cane growers, medium size growers, and smallholder cane growers, who account for $77 \%, 17 \%, 5 \%$, and $1 \%$ of the industry's total cane production (Swaziland Sugar Association, 2011). About 400 cane growers fall under the medium and smallholder farmers, while millers and large cane growers combine are only 10 . However, the medium and smallholder cane growers account for a small volume in terms of total cane production. The sugar industry is regulated by the Swaziland Sugar Association (Sugar Act of 1967). Any differences among the industry players are attended to by the Swaziland Sugar Association. Currently the sugar industry is going through a process of expansion as a result of the Swaziland Komati Downstream Development Project (KDDP) and the Lower Usuthu Smallholder Irrigation Project (LUSIP).

Table 1 shows the sugarcane production statistics in Swaziland from 2006 to 2011. Among the sugarcane produced is that from smallholder sugarcane growers. The statistics show a decline in the area under cultivation in the 2008/09 production year which also resulted in a decline in the sugarcane yield as well as the sucrose yield.

Table1. Sugarcane production statistics in Swaziland

\begin{tabular}{llllll}
\hline Item & $2006 / 2007$ & $2007 / 2008$ & $2008 / 2009$ & $2009 / 2010$ & $2010 / 2011$ \\
\hline Area cultivated (ha) & 52233 & 52255 & 52068 & 52822 & 53372 \\
Area harvested (ha) & 50400 & 50245 & 50375 & 50502 & 50473 \\
Cane production (tonnes) & 4930938 & 5075693 & 4912949 & 4908152 & 4862302 \\
Cane yield (tonnes/ha) & 97.8 & 101.0 & 97.5 & 97.2 & 95.9 \\
Sucrose content (\%) & 14.4 & 14.3 & 14.6 & 14.3 & 13.9 \\
Sucrose production (tonnes) & 711504 & 724716 & 716718 & 702825 & 675909 \\
Sugar production (tonnes) & 623357 & 631236 & 626984 & 605657 & 582019 \\
\hline
\end{tabular}

Source: Swaziland Sugar Association (2011).

From the 2009/10 production year, the area under cultivation shows an increase although the sucrose production decreased (Swaziland Sugar Association, 2011).

\subsection{The Concept of Productivity}

According to Mulwa et al. (2005), productivity refers to the ratio of output to a single input or rather resources used to produce output. However, when all inputs and all outputs in a system are used it is called total productivity. Therefore, productivity is the efficiency with which output is produced from a given set of inputs (Reddy, 1998). Productivity in this study refers to refers to sugarcane output per hectare of land. The primary concern of sugarcane growers and the sugar industry is to achieve the highest sugarcane productivity and high sugar recovery both of which support maximum economic return (Singh et al., 2008).

The United Nations (2000) reported that the area under cultivation by the smallholder sugarcane growers and the sucrose produced by them rose rapidly since 1992, when the growers cultivated less than 200 hectares and produced less than 2000 tonnes of sucrose. In 1998, excluding Vuvulane Irrigation Farm, smallholder sugarcane growers cultivated just under 1200 hectares, producing 84000 tonnes of cane and 11000 tonnes of sucrose. In 2006 they produced 82508 tonnes of sucrose constituting $11 \%$ of the total production (Technoserve, 2007). The introduction of the smallholder sugarcane growing has allowed the commercialisation of an otherwise under-utilised land and has contributed to increased throughput for the mills. According to Malaza and Myeni (2009) the poor performance of the existing smallholder sugarcane farmers' associations has require investigation. This study seeks to identify the factors that affect the productivity of sugarcane in the study area. 


\subsection{Factors affecting Smallholder Sugarcane Productivity}

According to Azam and Khan (2010), agricultural productivity is greatly affected by a number of inputs such as land, labour, capital, seed, fertilizer, irrigation and soil. All the inputs are categorized into three main variables such as land, labour and capital, where land includes the rental value of land for 12 months and labour consists of the hired labour, and family labour.

According to Malaza and Myeni (2009), it is important that smallholder cane growers improve their yield and sucrose content in order to maximise income. The major determinant of sugarcane productivity is timely and adequate application of inputs through the life cycle of the crop. Lower input use will certainly save costs, but reduce productivity. It is further argued that the age of ratoon has an inverse relationship with crop yield. If no new sugarcane is planted that implies declining trend in productivity. Malaza and Myeni (2009) identified seed, fertilization, irrigation, transport costs and ratoon management as the key elements to be managed for efficient production. The right varieties for the climate and soils need to be grown. Land has to be prepared taking into consideration the method of irrigation to be used and it should facilitate proper water movements.

Narayan (2004) estimated a sugarcane production model of sugarcane production in Fiji and found that the area harvested and fertilizer, labour force and prices paid to sugarcane farmers had positive influence on sugarcane productivity and profitability in both the short- and long-run.

Ogwang (2009) used Cobb-Douglas production function to determine factors affecting sugarcane productivity while gross margin analysis was used to determine profitability of sugarcane production. The results indicated that sugarcane farmers were getting positive gross margins from their sugarcane enterprise. The Cobb-Douglas results revealed that sugarcane acreage (farm size), amount of labour used and the distance from farms to factory were statistically significant.

Baiyegunhi and Arnold (2011) investigated the economics of sugarcane production in Eshowe and Entumeni areas of KwaZulu-Natal. Sugarcane yield per hectare was used as the dependent variable and the explanatory variables included in the model were farm size (that is, the area of land devoted to sugarcane, measured in hectares) and other explanatory variables were stated in financial terms(Rands/hectare), these were farm staff, fertilizer, chemicals, fuels/lubricants and machine maintenance. The results showed that all the explanatory variables were significant in explaining the sugarcane yield per hectare.

According to Hasan (2008), factors that affect maize yield include seed rate, human labour, manure, fertilizer, and irrigation water use. These variables were considered as a priori explanatory variables responsible for variation in maize yield. The individual effect of these inputs and factors can be explained to a certain degree by multiple regression analysis. The Cobb-Douglas model was selected for the analysis because it is generally considered superior on theoretical and econometric grounds for determining the effects of variable inputs. It also allows for regression under Ordinary Least Squares (OLS) in logarithm, yields coefficients which represent production elasticity and if all the inputs related to the production were taken into account as the independent variables, the sum of the production elasticities indicated whether the production process as a whole yield has increasing, constant or decreasing returns to scale.

Hussain and Khattak (2008) studied the economics of sugarcane production in and found that the area under sugarcane, total fertilizer used, total pesticides and insecticides used, human labour, tractor labour and total seed cane used were the main factors affecting sugarcane production.

\section{Methodology}

The study focused on smallholder sugarcane farmers' associations under KDDP. These are located in the Lowveld of Swaziland, with the farms nestled along the Komati River from Madlangempisi, down to Mananga Border Gate in the North-Eastern Swaziland. The KDDP area was purposively chosen for this study because the farmers' associations operate in homogenous agro-climatic conditions and sugarcane is the major crop enterprise in the area. The study made use of data from 15 smallholder sugarcane farmers' associations under KDDP and it covered a period of 2004/2005 to 2010/2011 production seasons.

Data were analysed using descriptive and inferential statistics. The Statistical Package for Social Sciences (SPSS version 17) was used to analyze the data. The descriptive statistics used include means, standard deviation, while the Cobb- Douglas Production Function (CDPF) was used for inferential statistics.

\subsection{Econometric Model}

The Cobb- Douglas Production Function (CDPF) was chosen for the purpose of data analysis when investigating the factors affecting sugarcane productivity in the study area. The selection of CDPF was based on that it can 
handle multiple inputs in its generalized form, in the presence of imperfections in the market it does not introduce distortions of its own and various econometric estimation problems like serial correlation, heteroscedasticity and multicolinearity can be handled adequately and easily. Further, it facilitates computations and has the properties of uniformity, representability, and flexibility (Baiyegunhi \& Arnold, 2011). The general form of the Cobb-Douglas production function is;

$$
\mathrm{Y}=\beta_{0} \mathrm{X}_{1}{ }^{\beta 1} \mathrm{X}_{2}{ }^{\beta 2} \mathrm{X}_{3}{ }^{\beta 3} \mathrm{X}_{4}{ }^{\beta 4} \mathrm{X}_{5}{ }^{\beta 5} \mathrm{X}_{6}{ }^{\beta 6} \mathrm{e}^{\mu}
$$

Where;

$\mathrm{Y}=$ Productivity (yield/ha)

$\beta_{0}=$ Constant

$\beta_{\mathrm{i}}=$ output elasticities

$\mathrm{X}_{1}=$ Farm size (ha)

$\mathrm{X}_{2}=$ Labour (man days/ha)

$\mathrm{X}_{3}=$ Chemical (litres/ha)

$\mathrm{X}_{4}=$ Basal fertilizer $(\mathrm{kg} / \mathrm{ha})$

$\mathrm{X}_{5}=$ Urea $(\mathrm{kg} / \mathrm{ha})$

$\mathrm{X}_{6}=$ Irrigation $(\mathrm{hrs} / \mathrm{ha})$.

$\mathrm{e}=$ error term

Given the increasing input prices in the sugarcane industry and management objective to minimize costs, a double-log production function was estimated using the total sugarcane harvested in tonnes (per hectare) as dependent variable subject to the production inputs. This was used to determine factors affecting sugarcane productivity. The CDPF was linearized so that it could be linear in the parameters and, hence easier to interpret. Hence;

$$
\ln \mathrm{Y}=\beta_{0}+\beta_{1} \ln \mathrm{X}_{1}+\beta_{2} \ln \mathrm{X}_{2}+\beta_{3} \ln \mathrm{X}_{3}+\beta_{4} \ln \mathrm{X}_{4}+\beta_{5} \ln \mathrm{X}_{5}+\beta_{6} \ln \mathrm{X}_{6}+\mu .
$$

\subsection{Explanation of Variables and A Priori Expectations}

Productivity (Y): This is the dependent variable in the model and it is measured in sugarcane yield per hectare (tonnes/ha). It measures the amount of sugarcane yield the farmers' associations were able to produce per hectare. The explanatory variables included in the model are farm size (that is, the area of land devoted to sugarcane, measured in hectares) labour (man days/ha), chemicals (litres/ha), basal fertilizer ( $\mathrm{kg} / \mathrm{hectare})$, urea $(\mathrm{kg} / \mathrm{ha})$ and irrigation time (hrs/ha).

Farm size $\left(\mathrm{X}_{1}\right)$ : In the case of smallholder sugarcane farmers' associations it is expected that they do not have the managerial capacity of producing in large farms. However, these associations have skilled personnel to manage the farms so it may depend on the individual farm capability and as such the relationship between farm size and sugarcane yield per ha cannot be pre-determined.

Labour $\left(\mathrm{X}_{2}\right)$ : Sugarcane production is labour intensive and high amount of labour is required for the various operations that take place during the course of the production season. As such in order to produce a good crop a considerable amount of labour is needed to carry out all the work. A positive relationship between labour and yield per hectare is expected.

Basal fertilizer $\left(\mathrm{X}_{3}\right)$ : An adequate amount of fertilizer application is vital for the growth of a good sugarcane crop. It is vital that adequate amount of fertilizer is applied so that the crop gets all the required nutrients to produce a good yield. A positive relationship is expected between the amount of fertilizer and the yield per hectare.

Urea $\left(\mathrm{X}_{4}\right)$ : The application of fertilizer at a later stage is crucial for the vegetative growth of the sugarcane crop and the timely and adequate application of a top dressing fertilizer is necessary. Urea application boosts the growth of sugarcane and as such a positive relationship is expected between urea and sugarcane yield per hectare.

Chemical $\left(\mathrm{X}_{5}\right)$ : Chemicals need to be applied to protect the crop from pests and diseases and also as a means of weed control. Their adequate and timely application is important and hence a positive relationship between chemicals and sugarcane yield is expected.

Irrigation time $\left(\mathrm{X}_{6}\right)$ : Sugarcane needs a lot of water for its optimum growth and with rainfall patterns that are erratic, irrigation is a must. Adequate application of irrigation water is, therefore, expected to result in good 
yields in sugarcane production. A positive relationship is thus expected between irrigation time and sugarcane yield per hectare.

\section{Results and Discussion}

Farm characteristics in the sampled area are presented in Table 2. The average farm size under sugarcane cultivation is 164.37 ha and an average output of 16511.54 tonnes per season is produced. The minimum and maximum farm sizes are 42.80 ha and 336.30ha respectively with corresponding outputs of 1991 tonnes and 34638.9 tonnes per season, indicating that an increase in farm size will result in an increase in the average output.

Table 2. Farm and input use characteristics of smallholder sugarcane farmers' associations underKDDP

\begin{tabular}{llcll}
\hline Variable & Mean & Standard Deviation & Minimum & Maximum \\
\hline Sugarcane yield (tonnes) & 16511.54 & 7662.91 & 1991.00 & 34638.9 \\
Sugarcane yield (tonnes/ha) & 100.82 & 12.24 & 69.00 & 139.00 \\
Farm size (ha) & 164.37 & 75.09 & 42.80 & 336.30 \\
Labour (man days/ha) & 31.25 & 3.47 & 32.5 & 35.80 \\
Basal fertilizer (kg/ha) & 456 & 62.08 & 400 & 759 \\
Urea (kg/ha) & 225 & 38.78 & 217 & 260 \\
Chemicals (litres/ha) & 14.3 & 3.09 & 10.92 & 16.22 \\
Irrigation time (hrs/ha) & 98.43 & 12.76 & 78.87 & 143.54 \\
\hline
\end{tabular}

The sugarcane yield per hectare ranged from 69 tonnes to 139 tonnes and the mean yield per hectare was 100.82 tonnes. Labour share in the production constitutes a mean of 31.25 man days per hectare. Basal fertilizer is varying in large amounts among the associations with a range of $400 \mathrm{~kg} / \mathrm{ha}$ to $759 \mathrm{~kg} / \mathrm{ha}$, indication of the constraint in accessing operational loans which then forces farmers' associations not to apply the optimum amounts of inputs.

\subsection{Production Elasticities}

The empirical result of the double-log equation is presented in Table 3. The results show that all the explanatory variables were statistically significant in influencing sugarcane yield per ha except for chemicals and time of irrigation. Farm size, labour, basal fertilizer, and urea have elasticities of $1.038,0.943,0.921$, and 0.760 respectively. The coefficient of 1.038 for farm size was statistically significant $(\mathrm{p}<0.01)$ and implies that a one percent increase in the land under sugarcane production results in the yield increasing by 1.038 percent. This result may be due to the fact that farm managers are trained personnel and they can successfully manage the farms and produce a good crop.

Labour had a coefficient of 0.943 and statistically significant $(\mathrm{p}<0.05)$. This means that for one percent increase in the amount of labour used, there would be a 0.943 percent increase in the sugarcane yield per hectare realized. This result was in agreement with the a priori expectation and it also concurred with findings by Narayan (2004) and Ogwang (2009) that labour is positively related to output in sugarcane production.

Both basal fertilizer and urea were statistically significant at 1 percent and 5 percent respectively and these results were also in agreement with a priori expectations in the study. The coefficient of 0.921 for basal fertilizer suggested that a percent increase in the amount of basal fertilizer applied would result in a 0.921 percent increase in yield per hectare. The same would be expected from urea, where a one percent increase in the amount of urea applied resulted in a 0.760 percent increase in the sugarcane yield per hectare. The positive significance of fertilizer was in line with Hussain and Khattak (2008) who found that the use of chemical fertilizer increases sugarcane productivity when it is applied at appropriate time and using the corre dosage.

Chemicals variable was statistically insignificant with a coefficient of 0.428 . This was probably due to the fact that the sugarcane crop is not prone to many pest and diseases if proper management is practiced. The notable use of chemicals is in controlling weeds.

Irrigation was the other variable that was not significant and this was contrary to a priori expectations. This may be attributed to the fact that the farmers in the study area use the same type of irrigation system and hence there 
is minimal variation in the time spent irrigating the field and the amount of water used by the sugarcane crop.

Table 3. Estimates of the factors affecting productivity of KDDP smallholder sugarcane farmers' associations

\begin{tabular}{lll}
\hline Variable & Coefficients $\left(\beta_{\mathrm{i}}\right)$ & t-statistics \\
\hline Constant & $3.439^{*}$ & 2.333 \\
lnFarm size & $1.038^{* *}$ & 18.352 \\
lnLabour & $0.943^{*}$ & 2.048 \\
lnBasal fertilizer & $0.921^{* *}$ & 2.181 \\
lnUrea & $0.760^{*}$ & 3.412 \\
lnChemicals & 0.428 & 1.615 \\
lnIrrigation time & 1.33 & 1.323 \\
$\Sigma \beta_{\mathrm{i}}=3.052$ & Durbin-Watson $=1.949$ & \\
$\mathrm{R}^{2}=0.71$ & F. statistic $=58.2$ & \\
$\quad$ Adjusted $\mathrm{R}^{2}=0.68$ & Df $=104$ &
\end{tabular}

The summation of the elasticities of production for all inputs provides an indication of returns to scale, given that no relevant factors were left out. In this study the returns to scale value was 3.052 implying an increasing returns to scale. This is because the proportionate increase in the input mix resulted in a greater than proportionate increase in production. The F-statistic of 58.2 explains the relationship between the dependent variable and the independent variables. This, therefore, implies that there is a significant relationship between sugarcane yield per hectare and the explanatory variables and hence the null hypothesis can be rejected.

\section{Conclusions and Recommendations}

The study sought to assess the factors affecting smallholder sugarcane productivity. It can be concluded that labour, basal fertilizer and urea are important in ensuring sugarcane productivity. It is, therefore, vital that in order for the smallholder sugarcane farmers' associations to realise higher yields per hectare, they have to apply the optimum amounts of the inputs and at the right time. Proper crop husbandry is also important so that a good crop is produced. It is recommended that sugarcane farmers need to apply the recommended amount of basal fertilizer and the recommended top dressing fertilizer. Farmers also need to increase the land allocated to sugarcane production in order to benefit economies of scale. The Government, through the Ministry of Agriculture and Cooperatives, and the private sector should intensify the out-grower technical services rendered to sugarcane farmers so that they can improve the productivity of sugarcane farming.

\section{References}

Azam, M., \& Khan, M. (2010). Significance of the sugarcane crops with Special reference to NWFP, Sarhad Journal of Agriculture, 26(2), 289-295.

Baiyegunhi, L. J. S., \& Arnold, C. A. (2011). Economics of sugarcane production on large scale farms in the Eshowe/Entumeni areas of KwaZulu-Natal, South Africa. African Journal of Agricultural Research, 6(21), 4960-4967.

Hasan, M. (2008). Economic Efficiency and Constraints of Maize Production in the Northern Region of Bangladesh. Journal of Innovative Development Strategy, 1(1), 18-32.

Hussain, A., \& Khattak, N. (2008). Economics of Sugarcane crop in District Charsadda. Journal of Agricultural Research, 49(1), 153-163.

Malaza, S., \& Myeni, D. M. (2009). Integrating Smallholder Growers into competitive sugarcane production. South African Sugarcane Technologists Association, 82, 405-408.

Mulwa, R., Nuppenau, E. A., \& Emrouznejad, A. (2005). 'Productivity of Smallholder SugarcaneProducers in Kenya: A Malmquist TFP Decomposition,' A paper presented in The Tropentag, Stuttgart Germany, October, 2005. 
Narayan, P. K. (2004). An empirical analysis of sugarcane production in Fiji, 1970-2000. Economic analysis and policy, 34(1), 53-62.

Ogwang, H. J. (2009). Production and profitability of sugarcane among Kinyaracane Out- growers, Masindi District. Unpublished Master's Thesis, Faculty of Agriculture, Makerere University Research Repository.

Reddy, M. V. (1998). Production and Economic Analysis of Fiji's Sugar Industry, Unpublished PhD Dissertation, Department of Agriculture and Resource Economics, Hawaii.

Singh, V. K., Shukla, A. K., Gill, M. S., Sharma, S. K., \& Tiwari, K. N. (2008). Improving Sugarcane Productivity through Balanced Nutrition with Potassium, Sulphur, and Magnesium, Better Crops- India: 12-14.

Sugar Act. (1967). Swaziland Sugar Industry Act. Mbabane, Swaziland.

Swaziland Sugar Association. (2011). Swaziland Sugar Association Annual Report, Mbabane, Swaziland.

Technoserve. (2007). Improving Income and Opportunities for Swaziland's Smallholder Sugar Farmers. Presentation to Swaziland Sugar Industry, Mbabane, Swaziland.

Thompson, F. T. (2007). Swaziland Business Year Book. Christina Forsyth Thompson, Mbabane, Swaziland.

Thompson, F. T. (2010). Swaziland Business Year Book. Christina Forsyth Thompson, Mbabane, Swaziland.

UNCTAD. (2000). Policies for small-scale sugar cane growing in Swaziland. Report prepared for United Nations Conference on Trade and Development (UNCTAD) under project SWA/99/A06.

United Nation conference on Trade and Development, (2000). Policies for Small-Scale Sugarcane Growing. A Report on Policies for Small-Scale Sugarcane Growing in Swaziland, Mbabane, Swaziland.

Westlake, M. J. (1995). Prospects for Swaziland's sugar industry in SACU. Ministry of Finance-European Development Fund: 7ACP SW 030, Mbabane, Swaziland. 